\title{
Higher Education and the Digital Rapids
}

\section{Frank Newman \\ Jamie E. Scurry}

Frank Newman is director of the Futures Project: Policy for Higher Education in a Changing World. Jamie E. Scurry is research associate at the Futures Project. Address: The Futures Project, Box 1977, Brown University, Providence, RI 02912, USA. E-mail: <Jamie_Scurry@brown.edu>. URL: $<w w w$. futuresproject.org $>$.

$\mathrm{O}$ ver 1,100 colleges and universities in the United States, as well as hundreds of institutions in other countries, are now offering courses on the Internet. As enrollments soar, learning on-line continues to meet many students' needs. A growing body of research is demonstrating that on-line learning can be both effective and satisfying. In the next few years, we can expect even more spectacular growth in virtual education. Yet the tendency of people within as well as outside higher education to focus on distance education has obscured what will be a far more important phenomenon: the impact of digital technology on pedagogy, especially in the traditional classroom.

\section{The Computer in the Classroom}

In the United States, the use of the computer and the Internet on campus is steadily growing. Thus far, most faculty members have used technology to perform ordinary tasks more efficientlyproviding course syllabi and readings, establishing communications links between faculty members and students as well as among students, and creating the means to improve student research. Increasingly, however, more sophisticated software is emerging that directly engages students in active-effective learning. Based on our analysis at the Futures Project: Policy for Higher Education in a Changing World, a higher education think tank housed at Brown University, we estimate that over the next five or six years, the use of such software will become commonplace. It will transform the way learning occurs in most, though not all, college classrooms.

The evidence shows that, when students actively participate in a self-driven learning project, they learn and retain more than when they sit and listen passively. Yet a recent study conducted by the Higher Education Research Institute at the University of California at Los Angeles for the Policy Center on the First Year of College, based at Brevard College in North Carolina, found that, while lecturing was the most common methodology, only 21.4 percent of students favored that approach.

Digital technology can allow professors to use teaching methods that are far more effective than lecturingand without a lot of extra time and effort.

\section{Active and Personalized Learning}

New software gives students hands-on experiences in any subject and is particularly valuable in scientific areas that require laboratory work. For example, to provide experience with sophisticated instrumentation for an introduc-

tory chemistry class of 100 or 200 students requires an exorbitant amount of equipment and staff time. Software now allows students to analyze a sample or change the parameters of an experiment in a virtual way-substantially enriching an otherwise abstract and passive class. It also allows every student to conduct a range of experiments, not just single, simple, preset experiments.

Moreover, because actual laboratory experience is still essential, virtual lab time allows more efficient and effective use of real laboratory facilities. Take the measurement of infrared spectra, a fundamental part of lab work in chemistry: the instruments usually require a detailed technical introduction by a professor, but working on the Web, students can measure simulated spectra until they are confident enough to carry out real measurements in the lab in an efficient manner.

\section{A growing body of research is demon- strating that on-line learning can be both effective and satisfying.}

\section{Virtual Reality Training}

The emergence of virtual reality technology offers a training supplement for surgeons - a faster, safer, and less costly way to enable students to practice surgical procedures. The software, which can be surprisingly realistic, allows the student to practice a wide range of surgical procedures, repeating each one with somewhat different conditions, until the student is comfortable with the process and ready for the traditional modes of surgical practice. This reduces the risks to patients and the need for expensive use of animals in training.

Faculty could make at least some of the improvements in learning outlined here without using digital technology, but this would require an extraordinary commitment of time and effort on the part of faculty members and students. With limited effort, the new digital technology simply makes learning much more interesting — even exciting.

\section{Future Developments}

The technology in use today is crude and limited compared with what will emerge over the next few years. One need only look at the evolution of computer games to recognize the potential for engaging students. As the inexorable 
improvement in digital technology and our understanding of it continues, we will experience further improvements in its capacity, reliability, cost-effectiveness, and ease of use. Soon it will be impossible, even with great effort, to achieve the same learning results without the use of the new technology.

\section{Higher education institution should recognize that digital technology has already begun to change how stu- dents learn.}

In looking ahead, every higher education institution should recognize that digital technology has already begun to change how students learn in every setting-online courses, elementary and secondary schools, and training centers as well as traditional classrooms. Indeed, as the capacity and use of technology continue to advance, the traditional classroom and the on-line course will look more and more alike to the student. Each venue will use technology to enhance learning, encourage active learning, and provide for frequent communication with faculty members and other students. In both settings, faculty members will move toward the role of mentors and guides of learning rather than as the primary sources of information.

All of these changes will raise important questions for higher education institutions. For example, the debate over technology has serendipitously moved the goal of improving teaching from the periphery to the center of the institution's concerns, raising the possibility of a renaissance in the efforts to improve the level of student learning. What incentives for faculty performance should institutions develop in response to the impact of new technology on pedagogy?

Moreover, those institutions skilled in the use of technology to improve learning will soon be seen as more dynamic and effective than their less-engaged competitors. Therefore, institutions and faculty members that focus on excellent teaching will need to excel in the use of technology to remain leaders in teaching. How should the institution support faculty members as they make this transition?

Finally, students, too, must be proficient at using digital technology. Every new wave of students arrives on campus with greater, but still uneven, experience in technology and with ever-higher expectations. What infrastructure and support should institutions provide students from all backgrounds to ensure a high level of technical expertise?

In short, as technology's impact on pedagogy becomes more profound, every institution will need to develop a strategy for its use. Higher education is in the digital rapids. And as any whitewater veteran will tell you, in such circumstances, it is far better to steer than to drift.

\section{International Experience, Attitudes, and Knowledge in the United States}

\section{Laura Siaya}

Laura Siaya is a research associate at the American Council on Education, Center for Institutional and International Initiatives. Address: One Dupont Circle, Suite 800, Washington, DC 20036. E-mail: <laura_Siaya@ace.nche.edu>.

T here is little debate anymore over the need for U.S. higher education to infuse an international dimension into course content, program offerings, and campus climate. National economies have become increasingly interdependent and leaders realize they need to work with other countries to ensure their own prosperity. This new reality has altered the world undergraduates will face following graduation. Knowledge of the international system, intercultural skills, and the flexibility to function in diverse environments is no longer the purview of just a few area studies or international relations majors. These are skills and knowledge essential for every undergraduate.

\section{The public views higher education as an important provider of international knowledge and skills.}

Unfortunately, as demonstrated in a recent American Council on Education (ACE) report, Preliminary Status Report 2000: Internationalization of U.S. Higher Education, by Fred M. Hayward, most colleges and universities are not adequately preparing students for these new challenges. The report reviewed the literature and found that foreignlanguage enrollments are lower now than in the 1960s, when compared to total enrollments; less than 3 percent of students will participate in a study abroad experience by the time they graduate; and only 7 percent of U.S. students have a minimal level of global preparedness skills and knowledge. Even more surprising was what the ACE review did not find. Despite the recent popularity and activity surrounding internationalization there is little documentation to assess its status and even less to suggest a positive impact on students.

To more fully examine the state of internationalization, in 2000 the ACE undertook two surveys. One used a national sample of 1,000 individuals 18 years of age and older to examine the extent of the public's international experience, attitudes about international education, and general knowledge about the rest of the world. The other survey, carried out in conjunction with the Art \& Science 